\title{
Negociación colectiva y conflicto laboral en Argentina (2003-2015): Entre la rutinización y la activación de las bases obreras
}

\author{
Collective bargaining and labour conflict in Argentina (2003-2015): Between \\ routinization and grassroots revitalization
}

Clara Marticorena*

Resumen: El objetivo del presente artículo consiste en analizar las dinámicas de negociación colectiva y conflicto laboral durante el período 2003-2015 en Argentina, considerando las tensiones que caracterizaron los procesos de negociación colectiva como modo de institucionalización del conflicto laboral y su impacto en la organización sindical. En particular, mostramos que los procesos de negociación colectiva se vieron signados por la integración del conflicto laboral y la presión de las bases obreras sobre las dirigencias sindicales.

Palabras clave: Negociación colectiva, conflicto laboral, organización sindical, trabajadores de base, Argentina.

\begin{abstract}
The aim of this paper is to analyze the dynamics between collective bargaining and labour conflict during the period 2003-2015 in Argentina, considering the tensions that this dynamic assumed as a way to institutionalize labor conflict. In particular, we show that the link between collective bargaining and labour conflict have been marked by the integration of labour conflict to the processes of collective bargaining and the pressure of grassroots workers' organization on union leaders.
\end{abstract}

Key words: Collective bargaining, labour conflict, union organization, grassroots workers, Argentina

Recibido: 23 agosto 2019 Aceptado: 3 diciembre 2019

\footnotetext{
* Argentina. Investigadora Adjunta del Centro de Estudios e Investigaciones Laborales-Consejo Nacional de Investigaciones Científicas y Técnicas (CEIL-CONICET) y docente de la Facultad de Ciencias Sociales de la Universidad de Buenos Aires (FSOC-UBA). Correo electrónico: claramarticorena@gmail.com
} 


\section{Introducción}

El objetivo del presente artículo consiste en analizar las dinámicas de negociación colectiva y conflicto laboral durante el período 2003-2015 en Argentina. En particular, busca indagar las tensiones asumidas por la negociación colectiva como modo de institucionalización del conflicto laboral, y el modo en que se vincularon a lo largo del período la dinámica de la negociación colectiva, el conflicto y los procesos de organización sindical.

Se busca poner en consideración la idea acerca de la negociación colectiva como modo de institucionalización del conflicto laboral y de qué modo abordar esta relación en la Argentina reciente. Para ello, se parte desde una lente distinta a la imperante en los estudios institucionalistas, donde el análisis de la negociación colectiva queda circunscripto a la relación entre las cúpulas sindicales y el Estado; pero también, desde una óptica distinta a la usualmente presente en los estudios críticos, donde la negociación colectiva es analizada únicamente como un mecanismo institucional sin incidencia en las prácticas sindicales de base y en la cotidianeidad de la construcción sindical.

Este trabajo se inscribe en el marco de un proyecto de investigación ${ }^{1}$ cuya principal hipótesis sostiene que la negociación colectiva ha sido clave durante los primeros años de la denominada postconvertibilidad para "ordenar" desde el Estado las relaciones laborales en un momento inicial de recomposición de la acumulación y la dominación, cuestionada por las movilizaciones populares de diciembre de 2001. Al mismo tiempo, considera que el dinamismo asumido por las negociaciones colectivas a lo largo de la última década operó como un factor clave en el impulso de la organización sindical en general, y de base en particular, y que dicho impulso moldeó determinadas formas de la práctica sindical en los lugares de trabajo, orientándolas y circunscribiéndolas a la lucha económica, sin mayores cuestionamientos sobre las relaciones de poder en el trabajo y las formas de explotación. En este sentido, el dinamismo de la negociación colectiva constituye un elemento relevante para comprender no sólo el avance en la organización de los trabajadores en su lugar de trabajo, sino también sus características, las cuales no se encuentran restringidas a las formas antiburocráticas y/o combativas emergentes durante el período, sino que también se han configurado de acuerdo a las prácticas sindicales tradicionales.

El análisis de la relación entre negociación, conflicto y organización sindical (a nivel de cúpulas y bases), permite observar el desarrollo de una dinámica resultante de procesos de "rutinización" / "normalización" de las relaciones laborales, que no dejan de entrar en tensión con la mayor organización, participación y activación de las bases obreras durante el período. Esto permite abordar críticamente los argumentos en torno a la configuración de una conflictividad "normal", propia de la dinámica industrial2. Al mismo tiempo,

\footnotetext{
1 Proyecto UBACYT La dinámica de la negociación colectiva y el conflicto laboral durante la postconvertibilidad en Argentina (2003-2015). Un estudio a partir de sectores seleccionados de la industria manufacturera, dirigido por Clara Marticorena, radicado en la Carrera de Sociología, Facultad de Ciencias Sociales, Universidad de Buenos Aires.

2 Este tipo de análisis es sostenido, por ejemplo, por Ricardo Spaltenberg en "La diversidad de los conflictos laborales: dispersión y centralización en las lógicas de acción de los asalariados privados", Trabajo, ocupación y empleo, 11, 2012, 95-118.
} 
refleja los procesos de institucionalización de la lucha de clases (y sus tensiones) operados durante los gobiernos kirchneristas. En dichos procesos fue clave la regulación estatal de las relaciones laborales en general, y en particular la negociación colectiva, así como el rol de los sindicatos tradicionales.

El trabajo aborda, en primer lugar, el análisis de la negociación colectiva como forma de institucionalización del conflicto laboral. Luego, se plantean algunos rasgos salientes de la relación entre negociación colectiva y conflicto laboral durante el período, considerando, posteriormente, el análisis del conflicto en el marco de los procesos de negociación colectiva y, la relación con los procesos de activación de las bases obreras. El análisis propuesto se basa en fuentes diversas: fuentes estadísticas sobre negociación y conflicto, fuentes documentales (convenios y acuerdos), y entrevistas semi-estructuradas realizadas a representantes sindicales $y$ patronales de distintos sectores de la industria manufacturera, así como a funcionarios del Ministerio de Trabajo, Empleo y Seguridad Social (MTESS), actualmente Ministerio de Producción y Trabajo ${ }^{3}$.

\section{La negociación colectiva como modo de institucionalización del conflicto laboral}

En el campo de las relaciones laborales, o, como se denomina en el medio anglosajón, las relaciones industriales (IR), es posible reconocer distintas tradiciones entre las cuales se destacan los enfoques pluralistas, los enfoques sistémico-funcionalistas, y la tradición marxista 4 . Uno de nuestros puntos de partida en el análisis de la negociación colectiva es ubicarla en su vínculo con la lucha de clases, rearticular en la lucha de clases a las instituciones laborales como parte resultante y, a la vez, condicionante del modo que adopta la relación capital-trabajo. Tomamos aquí el desarrollo de Hyman ${ }^{5}$, quien discutía con las visiones institucionalistas, por circunscribir el estudio de las relaciones industriales

\footnotetext{
${ }^{3}$ Las entrevistas fueron realizadas en distintos períodos: 2010-2011, 2013-2014 y 2016. Además de entrevistas a 5 funcionarios estatales, fueron entrevistados representantes sindicales (12 entrevistas -algunas a más de un entrevistado- a dirigentes sindicales, delegados y representantes legales de los sindicatos) y patronales de distintos sectores de la industria manufacturera (8 entrevistas). Asimismo, nos basamos en el análisis de la negociación colectiva de distintos sectores (químico, alimentación, textil, automotriz, aceitero, panadero y vestido) a partir de un relevamiento desarrollado inicialmente para nuestra investigación doctoral (Véase Clara Marticorena, Trabajo y negociación colectiva. Los trabajadores en la industria argentina, de los '90 a la posconvertibilidad, Buenos Aires, Imago Mundi, 2014) y continuado posteriormente en el marco de distintos proyectos de investigación. Nos basamos también en observación no participante tanto de plenarios sindicales como de audiencias de negociación colectiva.

4 Entre los autores que sistematizaron el campo de las relaciones industriales se destacaron los teóricos pluralistas de la "Oxford School", como Allan Flanders y Hugh Clegg, con el desarrollo de la negociación colectiva como mecanismo de la "democracia industrial". Por su parte, del enfoque sistémico se ha destacado particularmente el desarrollo de Dunlop, y dentro del enfoque marxista se destacan los trabajos de Richard Hyman, como análisis fundadores de la perspectiva crítica dentro del campo de las IR. Para una reconsideración crítica del campo de las relaciones industriales, véase John Kelly Rethinking industrial relations: mobilization, collectivism and long waves, London, Routledge, 1998.

5 Richard Hyman, Relaciones Industriales. Una introducción marxista, Madrid, Blume Ediciones, 1981.
} 
al conjunto de reglas y normas que regulan las relaciones obrero-patronales. Un ejemplo clásico de estas interpretaciones podemos encontrarlo en los estudios de J. Dunlop y Dunlop y Chamberlain6. Desde una perspectiva funcionalista, Dunlop concebía los sistemas de relaciones industriales como "...un complejo de reglas con el fin de gobernar el lugar de trabajo y la comunidad laboral." 7 según la cual los distintos "actores" (los obreros y sus organizaciones; los empresarios y sus organizaciones; y los organismos gubernamentales) poseen la misma capacidad de establecer las "reglas" que gobiernan las "relaciones industriales". Desde la perspectiva funcionalista el conflicto no es abordado como un elemento constitutivo de la relación capital-trabajo y el Estado posee un carácter neutral.

De acuerdo con Hyman definir de este modo el objeto de estudio de las relaciones industriales supone analizarlas desde la perspectiva del orden. Según el autor, el objeto de estudio de las relaciones industriales son los “...procesos de control sobre las relaciones de trabajo..." 8 , dentro de los cuales incluye la 'reglamentación' del trabajo, pero sobre la base del carácter contradictorio de la relación capital-trabajo. Este desarrollo permite plantear la negociación colectiva como un modo de institucionalización de la lucha de clases. Se trata de un proceso a través del cual se delimitan las relaciones entre obreros y patrones en el marco de los supuestos de la legalidad capitalista, y que circunscribe la lucha de clases a la lucha económica. En esta perspectiva, el Estado es reconocido como un Estado de clase, garante de la reproducción de las relaciones sociales capitalistas.

El autor marxista resaltaba el papel de las instituciones laborales como modo de control del conflicto laboral y planteaba que la integración de los sindicatos, los cuales tendían a reducir su función a la negociación colectiva, tendía a amortiguar la radicalidad de la acción sindical. Allí donde los teóricos de la regulación del trabajo pretendían ver una relación de 'cooperación antagónica', Hyman resaltaba la negociación colectiva como proceso de institucionalización del conflicto laboral. En este sentido, el teórico inglés cuestionaba las visiones pluralistas aplicadas a las relaciones industriales, que pretendían analizar la fábrica como un "estado democrático en miniatura". Efectivamente, desde estas perspectivas, la negociación colectiva era analizada como el mecanismo de la "democracia industrial"9.

Dicho esto, resulta necesario plantear que la negociación colectiva se ha constituido históricamente como modo de control del conflicto laboral pero también como modo de limitar el despotismo patronal. En este sentido resulta pertinente recuperar el concepto de legalidad industrial de Gramsci ${ }^{10}$. La noción de legalidad industrial expresa la conquista del reconocimiento de un conjunto de condiciones de trabajo por parte de la patronal a través de la acción de los sindicatos en tanto organización corporativa de la clase obrera. Es decir, representa a los obreros en su condición de vendedores de fuerza de trabajo. Esta legalidad

\footnotetext{
${ }^{6}$ John T Dunlop, Sistemas de relaciones industriales, Barcelona, Ed. Península, 1978; John T. Dunlop y Neil W. Chamberlain, Las negociaciones colectivas, Buenos Aires, Ediciones Marymar, 1971.

7 Dunlop, Op. Cit. 21.

8 Hyman, Op. Cit, 21. Cursivas en el original.

9 Veáse Hugh A. Clegg Sindicalismo en un sistema de negociación colectiva, Madrid, Ministerio de Trabajo y Seguridad Social, 1985.

10 Antonio Gramsci, Escritos periodísticos de L'Ordine Nuovo, Buenos Aires, Tesis Once, 1991.
} 
industrial, es también, por tanto, la que supone su reproducción como proletariado, como clase dominada y subordinada al capital. De este modo, la negociación colectiva permite establecer límites a la unilateralidad del despotismo patronal al tiempo que presupone la legitimación de la explotación del trabajo por el capital y su control del proceso productivo. Es, precisamente, este carácter contradictorio el que permite pensar las tensiones que atraviesan los mecanismos de regulación de la relación entre capital y trabajo. El concepto de legalidad industrial, a su vez, nos ayuda a cuestionar la conceptualización de la negociación colectiva como imperio de la democracia industrial proveniente del pluralismo anglosajón, en tanto opera una naturalización de la relación de explotación constitutiva del trabajo asalariado.

La caracterización de la negociación colectiva como un modo de institucionalización de la lucha de clases contempla que dicha institucionalización del conflicto de clases, históricamente, se despliega al tiempo en que se procesa la integración de la clase obrera y sus organizaciones sindicales y políticas a la sociedad capitalista. Es decir, dicha institucionalización, no significa necesariamente la anulación del conflicto, sino su modulación. Pero aun así es preciso considerar que la institucionalización de la lucha de clases es un proceso permanentemente en tensión, del mismo modo en que la subordinación del trabajo al capital se reproduce cotidianamente y no es un dominio constituido de una vez para siempre. En este sentido, Hyman señalaba que la "institucionalización del conflicto laboral logra de hecho una contención provisional del desorden..." 11 .

La concepción de la negociación colectiva como objeto y fin de la práctica sindical, constituye una de las dimensiones principales de la institucionalización del conflicto de clases. También en este punto, las perspectivas teóricas señaladas poseen distintas conceptualizaciones, de las cuales se derivan importantes consecuencias para el análisis teórico y político.

El rol de los sindicatos ha sido ampliamente debatido, no sólo en el seno de la tradición marxista, sino también dentro de la tradición pluralista y funcionalista, en tanto objeto permanente de preocupación de las clases dominantes. En el marco de los años dorados del capitalismo, estos debates tuvieron notable importancia en el campo de la sociología del trabajo y las relaciones industriales, donde la visión dominante sobre la función y rol de los sindicatos se redujo fuertemente a su función en la negociación colectiva. Este rol de los sindicatos en la lucha económica, restringido a la representación de los trabajadores en tanto asalariados, fue compartido por distintos enfoques no marxistas, en un momento signado por el contexto de la Guerra Fría12.

El contrapunto que desarrolla Flanders en su artículo "What are trade unions for?", en torno al análisis de Perry Anderson ${ }^{13}$ sobre el rol de los sindicatos, permite ilustrar las

\footnotetext{
11 Hyman, Op. Cit, 219.

12 Véase, por ejemplo, Michel Crozier, "Sociología del sindicalismo", Friedman G. y Naville P. Tratado de Sociología del Trabajo T II. México, FCE, 1971, 172-194; y Allan Flanders, “What are trade unions for?”, Management and unions, London, Faber and Faber, 1975, 38-47.

13 Perry Anderson, "Alcances y limitaciones de la acción sindical”, Alessandro Pizzorno, Perry Anderson, Serge Mallet, y Franco Momigliano, Economía y política en la acción sindical, Cuaderno $\mathrm{N}^{\circ} 44$. Buenos Aires, Ediciones Pasado y Presente, 1973, 57-73.
} 
concepciones en disputa. Allí, Flanders afirmaba que era preciso analizar el rol de los sindicatos por lo que hacían, resultando su rol principal la participación en los procesos de negociación colectiva. En una lectura pragmática de la acción sindical, planteaba que los trabajadores no se unían en sindicatos por compartir una perspectiva política o ideológica, sino que lo hacían para obtener mejoras en sus condiciones inmediatas. Su análisis irremediablemente se concentra en una de las dimensiones de las organizaciones sindicales, en términos más bien instrumentalistas, aunque Flanders no reducía la importancia de la negociación colectiva a la negociación mercantil, aspecto que cuestionaba en Sidney y Beatrice Webb, sino que la situaba en el plano de la regulación de las relaciones laborales ${ }^{14}$. El objetivo de la negociación colectiva era para él el establecimiento de reglas. Este análisis, si bien se distanciaba del liberalismo ortodoxo, relegaba la importancia de las organizaciones sindicales en la construcción del poder de la clase trabajadora. Ese es el aspecto en el cual se centra la discusión desarrollada por Anderson, acerca del rol de los sindicatos en la construcción de una alternativa socialista. En este punto, aun asumiendo los límites de la lucha económica dentro del capitalismo, Anderson rescataba la acción sindical por su importancia en la organización de los trabajadores en tanto clase opuesta al capital.

Si bien estos debates sobre el rol y carácter de la acción sindical tuvieron lugar en el contexto de ascenso de la lucha de clases durante la segunda posguerra, adquirieron renovada actualidad en el marco de la crisis capitalista contemporánea y las posibilidades de organización de la resistencia a las políticas de austeridad ${ }^{15}$. Su importancia no sólo radica en que continúan funcionando como las principales perspectivas teóricas que subyacen a los estudios sobre relaciones laborales y la acción sindical ${ }^{16}$, sino en que poseen relevancia en la práctica sindical y política actual. En nuestro caso, cobran una importancia renovada en el marco de un período signado por los debates en torno a la revitalización sindical y de significativo dinamismo de la negociación colectiva, como fue el período 2003-2015 en Argentina.

\section{La dinámica reciente del conflicto laboral y la negociación colectiva en Argentina}

La acción del Estado en el proceso de institucionalización del conflicto social luego de la crisis del 2001 fue particularmente activa, y estuvo caracterizada por la incorporación,

\footnotetext{
14 Allan Flanders, "Collective bargaining: a theoretical analysis", British Journal of Industrial Relations, Vol. 6, No $1,1968,1-26$.

15 Véase, entre otros, Heather Connolly y Ralph Darlington, "Radical political unionism in France and Britain: A comparative study of SUD-Rail and the RMT", European Journal of Industrial Relations, 18, 2012, 1-16; John Mc Ilroy, "Radical political unionism reassessed", European Journal of Industrial Relations, 22, 2012, 251-258; Martin Upchurch, y Andy Mathers, "Neoliberal Globalization and Trade Unionism: Toward Radical Political Unionism?" Critical Sociology, 38 (2), 2012, 265-280.

16 Tal como se desprende de los análisis de Kelly, Op. Cit. y Ralph Darlington en "The role of Trade Unions in Building Resistance: Theoretical, Historical and Comparative Perspectives", Maurizio Atzeni, Workers and Labour in Globalised Capitalism. Contemporary Themes and Theoretical Issues, London, Palgrave Macmillan, 2014, 111-138.
} 
adaptación y resignificación de reivindicaciones en contra del neoliberalismo y las políticas implementadas en la década del '90, como modo de recomposición de la dominación y acumulación en crisis. En un contexto signado por la crisis de hegemonía, tanto el gobierno de transición de E. Duhalde en 2002, como el de N. Kirchner a partir de 2003, buscaron recomponer la legitimidad estatal.

En el ámbito laboral, se destacó la política salarial, consistente en el otorgamiento de magros aumentos no remunerativos en el año 2002, como política de contención de la crisis, junto con el desarrollo del Programa de Jefes y Jefas de Hogar Desocupados. En 2003, la política salarial estuvo marcada por el aumento del Salario Mínimo, Vital y Móvil (que se encontraba congelado desde el año 1993) y por el decreto 392/2003, mediante el cual se dispuso la incorporación al salario básico en forma escalonada de sumas no remunerativas otorgadas previamente, a través de la negociación colectiva17. Este decreto resultó clave en la dinámica de la negociación colectiva posterior, como modo de encauzar a través de mecanismos institucionales las demandas y conflictos salariales surgidos en un marco signado por la profunda caída de los salarios reales en el año 2002 (luego de la devaluación) y la incipiente recuperación económica iniciada hacia finales de dicho año. Además de estas medidas, se sancionaron leyes que modificaron parcialmente las reformas laborales de los años '90 y el Estado adoptó una estrategia de mayor intervención en los conflictos laborales ${ }^{18}$.

El aumento del empleo (y el descenso del desempleo, y, por tanto, de su poder de disciplinamiento sobre la clase trabajadora), junto con la caída salarial fueron los principales determinantes objetivos del aumento de la conflictividad en los años 2004 y 2005, la cual estuvo protagonizada en gran medida por trabajadores ocupados, canalizada a través de organizaciones sindicales y con demandas fundamentalmente salariales. En este marco, se evidenció un significativo aumento en la cantidad de negociaciones colectivas (principalmente acuerdos salariales) (Tabla $\mathrm{N}^{\mathrm{o}} 1$ ), las cuales asumieron gran dinamismo y periodicidad, en función de la disputa de los trabajadores por recomposición del poder adquisitivo de sus salarios frente a la evolución de la inflación.

El dinamismo de la negociación colectiva se expresó principalmente en la firma de acuerdos de contenido salarial, siendo significativamente menor la firma de convenios colectivos de trabajo, aspecto que se profundiza frente a la aceleración inflacionaria posterior al año 2007. En cuanto a los contenidos no salariales negociados, se ha subrayado la permanencia de diversas cláusulas y condiciones de flexibilización laboral introducidas

\footnotetext{
17 En lo que sigue, conviene tener en cuenta que la Ley de Convenciones Colectivas de Trabajo ( $\left.\mathrm{N}^{\mathrm{o}} 14.250\right)$, establece: la atribución estatal - en tanto autoridad de aplicación - de la homologación de convenios y acuerdos para que entren en vigencia; el principio de ultraactividad, es decir que una vez vencida la convención colectiva sus cláusulas siguen vigentes hasta tanto las partes acuerden la celebración de otro convenio; y la cobertura «extensa» (erga omnes) de la negociación colectiva, es decir, que los convenios y acuerdos rigen para todos los trabajadores de la/s actividad/es para la/s cual/es rige la convención independientemente de su afiliación al sindicato firmante del convenio o acuerdo.

18 Sobre la regulación estatal de la relación capital-trabajo luego de la crisis de 2001, véase Alberto Bonnet, La insurrección como restauración. El kirchnerismo 2002-2015. Buenos Aires, Prometeo, 2015; Marticorena, Op. Cit. y Clara Marticorena, "Avances en el estudio de la relación entre sindicalismo y kirchnerismo". Sociohistórica. Cuadernos del CISH 36, 2015, 1-22.
} 
en los años '90, así como la usual incorporación de cláusulas de "paz social" en los acuerdos y convenios colectivos ${ }^{19}$.

Tabla N ${ }^{\mathrm{o}} 1$

Negociación colectiva en Argentina según tipo de negociación, 2002-2015

\begin{tabular}{cccc}
\hline Año & $\begin{array}{c}\text { Evolución de la } \\
\text { Negociaciones colectivas }\end{array}$ & $\begin{array}{c}\text { Convenios } \\
\text { colectivos de trabajo } \\
(\%)\end{array}$ & Acuerdos (\%) \\
\hline 2002 & 208 & 41,9 & 58,1 \\
2003 & 406 & 32,7 & 67,3 \\
2004 & 348 & 25,3 & 74,7 \\
2005 & 568 & 18,4 & 81,6 \\
2006 & 930 & 15 & 85 \\
2007 & 1027 & 14,4 & 85,6 \\
2008 & 1231 & 8,3 & 91,7 \\
2009 & 1331 & 6,4 & 93,6 \\
2010 & 2038 & 6,5 & 93,5 \\
2011 & 1864 & 5,7 & 94,3 \\
2012 & 1744 & 3,7 & 96,3 \\
2013 & 1699 & 4,1 & 95,9 \\
2014 & 1963 & 5,1 & 94,9 \\
2015 & 1957 & 5,3 & 94,7 \\
\hline
\end{tabular}

Fuente: Elaboración propia en base a MTESS (Ministerio de Trabajo, Empleo y Seguridad Social).

Existen distintas series sobre conflictividad laboral en Argentina, entre las más destacadas por su cobertura de carácter nacional se cuenta con las bases elaboradas por el Observatorio del Derecho Social de la Central de Trabajadores Argentinos (ODS-CTA-A), el Programa de Investigación sobre el Movimiento de la Sociedad Argentina (PIMSA), y la base elaborada por el MTESS. Esta última, releva la conflictividad laboral publicando las bases sobre conflictos con paro, y es la que adoptamos en este trabajo por el mayor alcance del relevamiento realizado respecto de las otras bases ${ }^{20}$.

19 Marticorena, Op. Cit. y Clara Marticorena, "'Revitalización sindical y negociación colectiva en Argentina (2003-2011)". Perfiles Latinoamericanos 46, 2015, 173-195.

20 Cada una de estas bases posee una metodología específica, definiendo distintas unidades de análisis, por ejemplo, PIMSA, releva "hechos de rebelión” (“...definido como todo hecho colectivo llevado a cabo por personificaciones de categorías económicas, sociales o políticas, dirigido contra alguna expresión del estado de cosas existente.", Programa de Investigación sobre el Movimiento de la Sociedad Argentina (PIMSA) "Los hechos de rebelión en Argentina 2002-2007", en Documentos y Comunicaciones, PIMSA, 2007.), mientras la serie del MTESS releva conflictos laborales, o más precisamente, conflictos colectivos de trabajo. En este caso "La unidad de análisis adoptada es el conflicto colectivo de trabajo, entendiendo por tal la serie de eventos desencadenados a partir de la realización de una acción conflictiva por parte de un grupo de trabajadores o empleadores con el objeto de alcanzar sus reivindicaciones laborales. Entre otras cosas, esto implica que en un mismo conflicto pueden llevarse a cabo varias acciones conflictivas." (Ministerio de Trabajo, Empleo y Seguridad Social (MTEySS) Metodología para el relevamiento, sistematización y análisis de los conflictos laborales colectivos, MTEySS, 2018, 2. Por su parte, el relevamiento del ODS tuvo un cambio metodológico en 2010, 
El gráfico 1 permite observar que las dinámicas de negociación colectiva (NC) y conflicto laboral (CL) se encuentran articuladas a lo largo del período analizado.

Gráfico $\mathrm{N}^{0} 1$ : Negociación colectiva y conflictividad laboral, 2005-2015. Evolución trimestral.

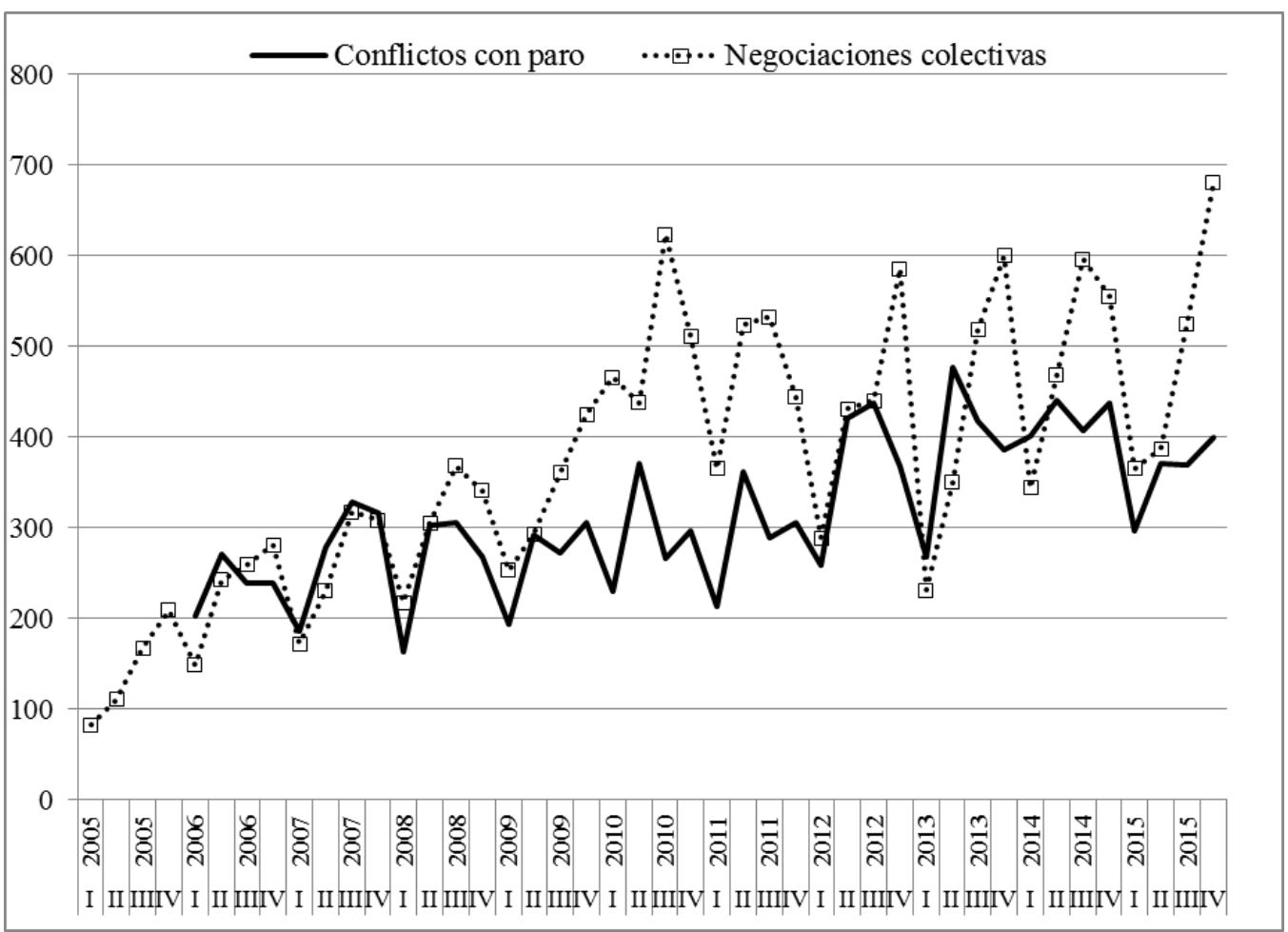

Fuente: Elaboración propia en base a MTESS.

Si vinculamos esta evolución con análisis que han abordado la dinámica del conflicto laboral es posible considerar que el acompañamiento entre las series de negociación colectiva y conflicto laboral en los primeros años de la serie coincide con el fortalecimiento de la Confederación General del Trabajo (CGT) como garante de la contención de la lucha económica entre capital y trabajo, luego del ascenso de conflictos motorizados por sectores independientes de los sindicatos tradicionales en los años 2004 y 200521. El cambio de dinámica que podemos observar a partir de 2009 puede deberse a la consolidación de la organización de base en los lugares de trabajo y de su participación en los procesos de

dificultando la evaluación del período en su conjunto. El relevamiento de PIMSA se basa en 4 diarios de alcance nacional (Clarín, La Nación, Página 12 y Crónica), mientras que el del MTESS releva 120 medios de prensa de todo el país y medios especializados en noticias gremiales. Si bien ello no implica significativos cambios en las tendencias generales, al comparar su evolución con la negociación colectiva, priorizamos el mayor alcance de la base del MTESS.

$21 \mathrm{Al}$ respecto, véase Matías E. Eskenazi, “Acumulación de capital y conflictividad laboral en argentina 20022009: Ejercicio de periodización e hipótesis de trabajo", XXVIII Congreso ALAS. Recife, Brasil, 2011. 
negociación colectiva, en un marco signado por la aceleración inflacionaria y el deterioro en el desenvolvimiento de la acumulación.

Sobre la evolución de la conflictividad en el período, los informes del MTESS y del ODS-CTA-A, señalan que en los primeros años se observa el predominio de conflictos por rama de actividad por motivos salariales mientras que a partir del año 2009 la dinámica se modifica en cuanto al tipo de reclamo, apreciándose una mayor descentralización del conflicto laboral. De acuerdo con el análisis del ODS-CTA-A, a partir de 2009 se observa un resurgimiento de conflictos por situaciones de crisis: despidos, suspensiones, cierre de establecimientos. Estos conflictos, que en el ámbito privado se desarrollan fundamentalmente a nivel de empresa, se van a mantener en los años siguientes, coexistiendo con los conflictos salariales por actividad.

Spaltenberg22 sostiene que en el período analizado se observa el resurgimiento del "conflicto industrial" a nivel de rama de actividad, caracterizado por huelgas de gran tamaño y corta duración. Sin embargo, señala que se aprecia un crecimiento en la cantidad de conflictos en el lugar de trabajo, que explican la evolución de la conflictividad en el ámbito privado, y darían cuenta de una mayor presencia sindical en los lugares de trabajo. De acuerdo con dicho análisis, el conflicto se explicaría por la dinámica de la negociación colectiva y estaría articulado por los sindicatos tradicionales. El trabajo destaca la "normalidad" del conflicto durante la postconvertibilidad asociándolo a lo que denomina "conflictos clásicos" en períodos de expansión de la economía y del empleo. Como veremos más adelante, si bien durante el período se consolida un nivel de conflictividad vinculado a los procesos de negociación, esta dinámica se encuentra tensionada con el avance de la organización de base, que interviene como elemento relativamente disruptivo, no sólo en los casos de oposición a las dirigencias sindicales.

Teniendo en cuenta la descentralización del conflicto laboral en el ámbito privado, cobra importancia analizar las características y dinámicas de los ciclos de negociación colectiva según nivel de negociación (Gráfico 2).

Si bien la negociación por empresa acompaña la negociación por actividad, en algunos períodos alcanza su punto máximo luego de las negociaciones por actividad, dando cuenta de la articulación de negociaciones de menor nivel con las de mayor nivel de agregación ${ }^{23}$, como en 2006, 2007, 2008, 2011 y 2013. También es interesante apuntar que, a diferencia de lo que sucede con las negociaciones de actividad, que alcanzan un pico máximo por año, en el caso de las negociaciones por empresa, en algunos años pueden observarse dos picos a lo largo del año, como en 2006, 2010 y 2012. Por su parte, en cuanto a la cantidad de negociaciones, en los años 2009 y 2010 las series se desacoplan por un aumento significativo de las negociaciones de empresa. Si bien posteriormente retoman una dinámica común, se mantiene la brecha entre las series de actividad y de empresa.

\footnotetext{
22 Spaltenberg, Op. Cit.

23 Como desarrollamos en otros trabajos, la descentralización del nivel de negociación colectiva constituyó parte de la ofensiva neoliberal profundizada en los años '90 en la Argentina y durante la postconvertibilidad se consolida un alto grado de descentralización. Al respecto, puede consultarse Clara Marticorena, "Relaciones de fuerza, relaciones laborales y estructura de la negociación colectiva. Alcances y características de la descentralización en Argentina", Trabajo y Sociedad 23 (XVII), 2014, 127-145.
} 
Gráfico $N^{\circ}$ 2: Convenios y acuerdos según nivel de negociación, 2005-2015. Evolución trimestral

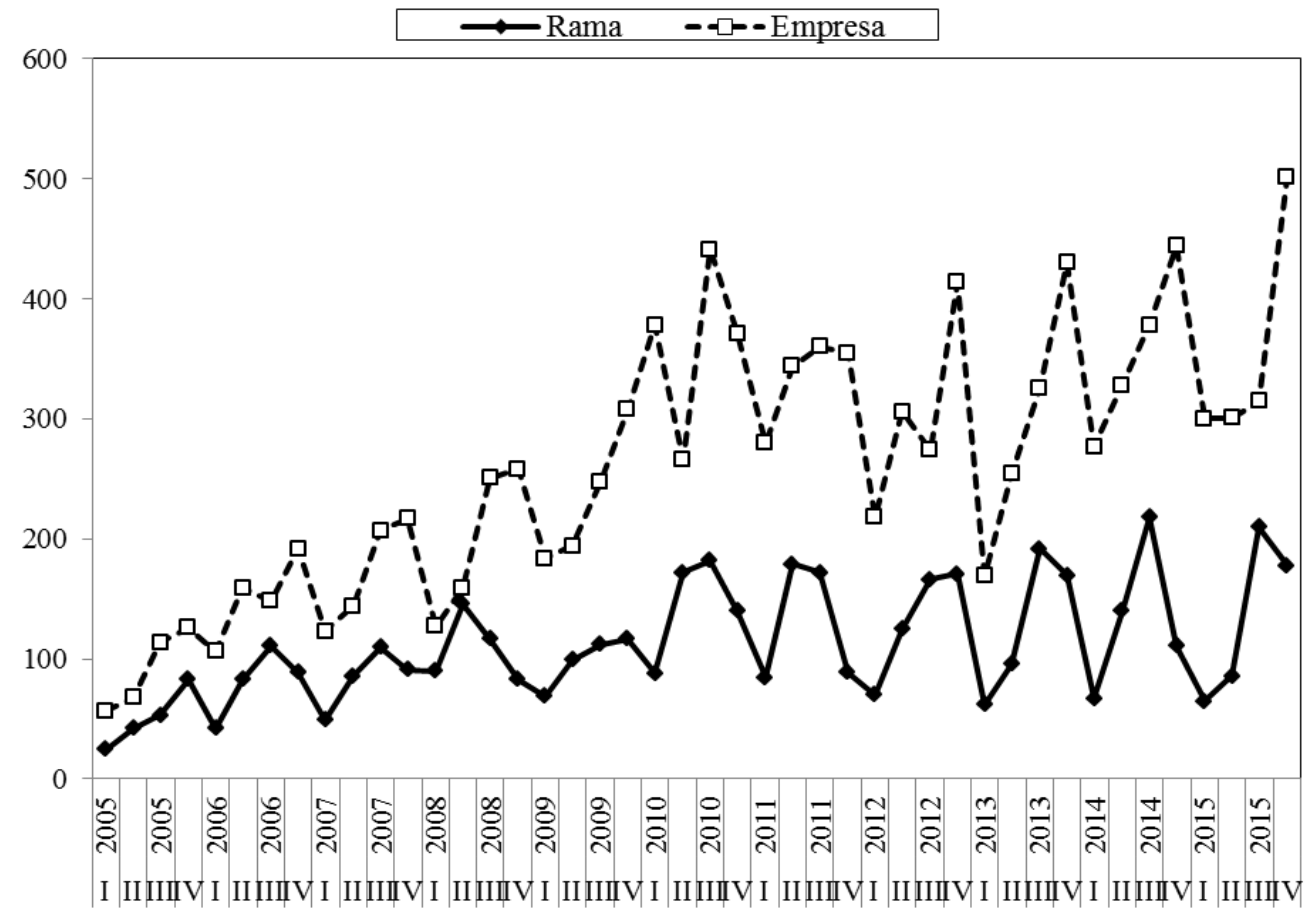

Fuente: Elaboración propia en base a MTESS.

¿Cómo se conjuga este proceso de mayor dinamismo de la negociación por empresa, con el proceso de descentralización de la conflictividad laboral? Si bien las tendencias a la descentralización de la negociación colectiva se vinculan con procesos de heterogeneización de la estructura productiva y han estado ligadas a un mayor avance de condiciones de flexibilización laboral24, es dable suponer que la descentralización del conflicto laboral refuerza la negociación en el nivel del lugar de trabajo. Al respecto, una funcionaria entrevistada planteaba que los conflictos no sólo se producen antes de la negociación sino también después, por incumplimiento del convenio:

...en general los conflictos se incrementan o antes o después de los incrementos salariales de la actividad. Antes porque es una forma ya de ir movilizando, que a lo mejor es por incumplimiento de cualquier cosa (...) Pero después también es por falta de cumplimiento de lo salarial o del complemento que se tiene en la empresa unido a lo salarial, que a veces las empresas tienen qué se yo, han dado a cuenta, bueno, cuando viene el incremento, o lo dieron a cuenta hace muchos meses, o hace dos años que lo están dando a cuenta y después lo quieren absorber, y así.

Entrevista, Funcionaria MTESS, 14 de mayo de 2014

24 Marticorena, Op. Cit. 
La evolución de las series y las entrevistas realizadas, permiten considerar que en sectores donde se negocia a nivel de rama y también de empresa, se establece una dinámica entre negociación de actividad y empresa, en donde primero se desarrolla la negociación de actividad, luego eso abre toda una serie de negociaciones por empresa, en general articuladas a dicha negociación por actividad, mediadas por conflictos en cada uno de estos niveles, como una de las características del período estudiado.

\section{El conflicto en el marco de los procesos de negociación colectiva}

La dinámica articulada entre negociación colectiva y conflicto laboral que observamos en el punto anterior, queda reflejada en el discurso de los/as entrevistados/as a través de distintas ideas, entre las cuales sobresale la idea de funcionalidad del conflicto respecto de la negociación colectiva, idea que fue posible identificar no sólo en entrevistas realizadas a funcionarios y representantes patronales, sino también a representantes sindicales. “Todos necesitan hacer un poco el show", nos dijo un abogado patronal ligado a la Unión Industrial Argentina (UIA), cuando lo consultamos acerca de la conflictividad laboral:

Yo te diría que en todos los sectores hubo un poquito más de conflictividad. Eh, y esto tiene (...) lógica en el sentido de que las propias autoridades consideran que el conflicto es virtuoso, o sea que desde el conflicto se sale con una mejora, etc., con lo cual, yo te diría, no hay sector que negocie sin tener presente que un poquito de ruido hay que hacer. Por ejemplo, en alimentación durante 20 años, no sé, desde el ' 86 que no había habido conflictos, y en los últimos 3 años, si bien no fueron conflictos grandes, siempre hay un par de días de paro durante la negociación. En químicos también. Y porque si no, la gente, digamos, lo que es el representado, considera que no se negoció con la suficiente dureza y que se podría haber obtenido algo más, por eso, digamos, todos necesitan hacer un poco el show.

Entrevista, Abogado patronal, 27 de julio, 2010

En el discurso patronal aparece retratada cierta "funcionalidad" del conflicto respecto de la negociación, que no es vista como un problema a menos que se vincule con sectores sindicales opuestos a las dirigencias tradicionales. También se observa cómo la patronal interpreta la intervención estatal durante el período analizado como favorable a la existencia de conflictos.

A su vez, en las entrevistas se plantea la idea de la maduración y de la no confrontación, del conflicto como una "etapa" de la negociación, resaltando la importancia de llegar a una negociación dentro de parámetros "normales":

Pregunta: ¿Qué cambios podés observar (...) en los procesos de negociación? En cuanto a la dinámica, a los participantes, a los contenidos. 
Respuesta: ...la forma en que los participantes, la forma en que los actores, la forma en que las partes, los negociadores se acercan a la negociación implica una dinámica distinta. Y, yo lo que he visto es que ha habido una maduración. Te diría que es una maduración en la conducta de los actores sociales. Se conocen, hace años que negocian, -cambiando algunas figuritas, qué se yo, siempre hay, en empresas o sectores empresarios...- pero en general ya todo el mundo se conoce, ya se tienen confianza o desconfianza porque ya saben, ¿no es cierto? (...) noto una mayor madurez. Las propias, los propios sindicalistas y los propios empresarios dicen "Y ya sabemos, ya estamos, ya...". No van a una confrontación por la confrontación. (...) El ejercicio y la experiencia de la negociación hacen que se entre de otra manera. E incluso, cuando por alguna circunstancia hay un sindicalista nuevo, o hay del sector empresario alguien nuevo, se observa que le dicen “No, mirá, lo que pasa es que vos no viniste otras veces, otros años, y entonces no sabés que esto viene de esta manera, pero después pasa esto y en realidad...". Es decir, nadie se asusta de la dureza de las primeras posiciones, digamos no se asusta en el sentido de no le choca ni cree que eso va a significar que vamos a estar peleando por siempre. Es decir, el hecho de que haya un conflicto inicial tampoco es tomado por ninguna de las partes como que es la hecatombe final. Es decir, todo el mundo sabe (...) que hay estadios y momentos, y lo aceptan, lo conocen por experiencia, saben que siempre al final se llega a la negociación y se acuerda dentro de parámetros de cierta normalidad, digamos para lo que es la actividad de que se trate. Esto es lo que yo he notado, hay una mayor madurez, reconocida por las propias personas. "Ya ustedes saben cómo somos", entonces los otros dicen "Sí, nosotros lo sabemos, los muchachos algunas veces se quejan, pero en realidad tienen coherencia con sus reclamos." Entonces eso muestra madurez de los actores sociales.

Entrevista, Funcionaria MTESS, 14 de Mayo de 2014.

Cabe retomar nuevamente a Hyman, cuando señalaba el ritualismo asumido por los métodos del conflicto industrial25. En este sentido, afirmaba que los paros se habían transformado en la continuación de las negociaciones por otros medios y que los reclamos de los huelguistas se habían convertido en "objetivos" negociables, marcando, precisamente cómo la negociación colectiva moldeaba la forma de expresión de la lucha de clases. Esta idea, según la cual el ejercicio de la negociación permite una menor confrontación aparece también en entrevistas a dirigentes sindicales, como contrapunto entre las aspiraciones de los delegados de base y la "moderación" que debe imprimir la dirección sindical. Una integrante de la comisión directiva del sindicato químico de Pilar planteaba lo siguiente respecto de la participación de los nuevos delegados y el reclamo por el cumplimiento del convenio colectivo de trabajo:

\footnotetext{
${ }^{25}$ Hyman, Op. Cit, 213.
} 
...al trabajador le genera cierta ansiedad de querer cambiar todo ya. Entonces, es un trabajo en el que nosotros acompañamos a los delegados, para que vayan planteando las cosas de a poco, porque en definitiva no es la actitud de destruir o de ir contra la empresa, sino de trabajar con la empresa para acomodar las cosas como tienen que ser. Es simplemente eso, y después de acomodar todo lo que dice nuestro convenio colectivo, se empieza a trabajar con las mejoras superiores, que son en cuestiones de, por lo general, de salario.

Entrevista, Miembro de comisión directiva del Sindicato Químico de Pilar, 30 de mayo de 2014.

\title{
5. Las tensiones abiertas con la participación de las bases obreras
}

\author{
Tanto la información estadística disponible ${ }^{26}$, como distintas investigaciones de tipo \\ cualitativo sobre casos y sectores específicos ${ }^{27}$, aportan evidencias que dan cuenta de una
}

\begin{abstract}
${ }^{26}$ Los trabajos de Trajtemberg, Berhó, Attorressi y Lauphan y de Trajtemberg, Medwid y Senén González mostraban que solamente el 12,4\% del total de empresas relevadas por el Módulo de Relaciones Laborales de la Encuesta de Indicadores Laborales (EIL-MTESS) contaba con la presencia de delegados sindicales. en los establecimientos de mayor tamaño (de más de 200 trabajadores) la presencia de delegados ascendía a 61,1\%; en los establecimientos medianos (de entre 50 y 200 trabajadores) era del 31\%, mientras que sólo en el 7,5\% de los pequeños establecimientos (de 10 a 50 trabajadores) contaban con la presencia de delegados. De todos modos, un relevamiento posterior realizado por el MTESS (Trajtemberg, Senén González, Borroni y Pontoni), correspondiente al año 2008, permitía observar un incremento en la presencia de delegados en las empresas relevadas, alcanzando el 70\% en grandes empresas, el 32\% en las medianas y $11 \%$ en las pequeñas empresas. Veáse David Trajtemberg, Fabián Berhó, Paula Attorressi y Walter Lauphan, “Encuesta de Relaciones Laborales", ponencia presentada en el $7^{\circ}$ Congreso Nacional de Estudios del Trabajo, ASET, Buenos Aires, 2005; David Trajtemberg, Bárbara Medwid y Cecilia Senén González, "La expansión de la afiliación sindical: Análisis del módulo de relaciones laborales de la EIL", Trabajo, ocupación y empleo 8, 2009, 13-34; y David Trajtemberg, Cecilia Senén González, Carla Borroni y Gabriela Pontoni, "Representación sindical en los lugares de trabajo: un análisis del Módulo de Relaciones laborales", Trabajo, ocupación y empleo 11, 2012, 119-142.

27 Véase Manuel Compañez, Patricia Ventrici y Federico Vocos, Metrodelegados. Subte: de la privatización al traspaso, Buenos Aires, Editorial Desde el Subte, 2012; Paula Lenguita y Santiago Duhalde, "El clasismo sindical en tiempos kirchneristas. Un estudio de caso", Conflicto social 7 (enero-junio), 2012, 43-68; Maurizio Atzeni y Pablo Ghigliani, "The re-emergence of workplace based organisation as the new expression of conflict in Argentina", Gregor Gall, New Forms and Expressions of conflict at work, London, Palgrave Macmillan, 2013, 6685; Cecilia Senén González y Andrea Del Bono (Coord.), La revitalización sindical en Argentina. Alcances y perspectivas, Buenos Aires, Prometeo/ UNLAM, 2013; Mariela Cambiasso, Tradición de organización y estrategias sindicales. Un estudio sobre la organización sindical en la fábrica alimenticia Kraft-Mondelez (ex Terrabusi) en la postconvertibilidad, Tesis de Doctorado no publicada, Universidad de Buenos Aires, 2015; Paula Varela, La disputa por la dignidad obrera. Sindicalismo de base fabril en la zona norte del Conurbano bonaerense 2003-2014, Buenos Aires, Imago Mundi, 2015; Paula Varela (Coord.), El gigante fragmentado. Sindicalismo, trabajadores y politica durante el kirchnerismo, Buenos Aires, Editorial Final Abierto, 2016; Lucila D’Urso, ¿Renovación de las estrategias sindicales en Argentina y Brasil? Los casos del SMATA y del Sindicato dos Metalúrgicos de ABC (2003-2014), Tesis de Doctorado no publicada, Universidad de Buenos Aires, 2017; Lucila D’Urso y Julieta Longo, “The radical political unionism as renewal strategy in Argentina", Latin American Perspectives, November 13, 2017, 1-17; Clara Marticorena, "Contribución al debate sobre la organización de base en la Argentina reciente a partir de la dinámica sindical en el sector químico", Conflicto Social 10 (18), 2017, 224-257.
\end{abstract}


mayor presencia de la organización sindical en los lugares de trabajo, expresada en un aumento de la representación sindical en los establecimientos.

Un modo de aproximación indirecta a los avances de la organización sindical en los lugares de trabajo ha estado dado por la evolución de la conflictividad en el lugar de trabajo. Sin embargo, constituye un debate abierto en qué medida el aumento de representación sindical en el lugar de trabajo expresa el crecimiento de sectores opositores a las dirigencias sindicales tradicionales, o refleja la mayor inserción de éstas entre las bases obreras.

Así, por ejemplo, Spaltenberg 28 plantea el carácter marginal de los conflictos protagonizados por sectores no alineados a las dirigencias tradicionales de los gremios, cuestionando la crisis o "debilidad" de las dirigencias en el lugar de trabajo. Según el artículo, en la mayoría de los conflictos del período analizado toda la organización sindical participa del incremento de la conflictividad. A partir de allí, establece una discusión con los desarrollos que plantean el surgimiento de un "sindicalismo de base" de carácter combativo y antiburocrático, señalando que durante la última década se observa un desarrollo de lo que denomina "sindicalismo en la base", que se expresa en el porcentaje relativamente pequeño de los conflictos protagonizados por instancias de base en conflicto con la dirigencia sindical o por fuera de la organización gremial frente a la importancia creciente de los conflictos en el lugar de trabajo. Sin embargo, aquí no se problematiza la relación entre el sindicalismo de base y en la base.

El análisis de Cotarelo $^{29}$ coincide en la importancia de la forma sindical como organización predominante de los "hechos de la rebelión" protagonizados por asalariados, fundamentalmente a partir de 2005-2006, pero señala un aumento a partir de 2004 de los hechos convocados por instancias sindicales como Comisiones Internas (CI) y Cuerpos de Delegados (CD), mayormente opositores a las direcciones sindicales. Al presentar la evolución se observa que el porcentaje de "hechos" realizados por "cuerpo de delegados, comisión interna o línea sindical" se incrementó significativamente siendo del $0.4 \%$ en $2002,2.8 \%$ en $2004,3.9 \%$ en $2006,11 \%$ en $2007,7.9 \%$ en 2008 , y $10 \%$ en 200930 .

Cabe señalar las dificultades para captar a través de los conflictos con paro (MTESS) la acción de líneas sindicales opositoras. Precisamente, por encontrarse en conflicto con la dirección del sindicato es dable suponer que la forma de expresión del conflicto no se realice a través de una huelga, sino de otro tipo de medidas. Este punto es importante para pensar las diferentes apreciaciones y ubicar el número resultante del relevamiento del MTESS. Es decir, que un sector opositor convoque un paro supone un nivel de organización y consolidación interna muy alto en relación con otras posibles acciones y es probable, entonces, que la mejor forma indirecta de observar el alcance de sectores de base opositores no sea principalmente la huelga sino otro tipo de medidas de fuerza.

La organización sindical de base no sólo se expresa en la dinámica del conflicto, sino también en las características de la negociación colectiva. Como señalamos anteriormente,

\footnotetext{
28 Op. Cit.

${ }_{29}^{9}$ María Celia Cotarelo, Argentina (1993-2010). El proceso de formación de una fuerza social, Buenos Aires, PIMSAImago Mundi, 2016.

30 Cotarelo, Op. Cit. 115.
} 
los altos niveles de negociación a nivel de empresa, característica afianzada con el avance del neoliberalismo en los años '90, suponen $\mathrm{y}$, a la vez, expresan la existencia de organización sindical en el lugar de trabajo. Asimismo, la mayor presencia sindical puede verse reflejada en convenios colectivos de trabajo y acuerdos celebrados a lo largo del período, ya sea a través de la participación de delegados en la firma de las negociaciones ${ }^{31}$, la inclusión de los delegados sindicales de planta en las comisiones de seguimiento del convenio o la mención explícita de sus funciones con respecto al cumplimiento del convenio, entre otros aspectos (crédito horario, realización de reuniones en el establecimiento, cuarto gremial, etc.).

El dinamismo de la negociación colectiva constituyó un factor de suma importancia en la organización de base, como modo de canalizar la defensa del convenio colectivo o la lucha por la conquista de un convenio colectivo por parte de un grupo de trabajadores si es que no tenían, así como por la importancia de la lucha salarial en un contexto de bajo desempleo y aceleración inflacionaria.

La presencia sindical en los lugares de trabajo se expresa tanto en la conflictividad como en los procesos de negociación colectiva. Estos procesos entran en tensión con la acción de la organización sindical de los trabajadores, en tanto el interés y la participación abren la posibilidad de la discusión sobre la orientación de la práctica gremial, del mismo modo que la organización de los trabajadores en sus lugares de trabajo detenta una potencialidad disruptiva en tanto se desarrolla en el locus de la dominación celular un espacio de politización obrera que puede exceder los reclamos económico-corporativos ${ }^{32}$. En este punto, el impulso de la organización de los trabajadores en sus lugares de trabajo puede constituir una amenaza para las dirigencias sindicales, por el sólo hecho de abrir la discusión en la base. Al respecto, un abogado sindical nos dijo:

Hay un aumento, creo yo sí, en la participación de los trabajadores. Hay muchos más delegados, no tengo estadísticas, pero por lo que veo yo de las asociaciones sindicales que por lo menos nosotros asesoramos es que hay mucha más participación de la gente (...). De base, de los trabajadores que se organizan, de los trabajadores que reclaman, de los trabajadores que piden elecciones, de gente interesada en postularse como candidato a ser delegado, que esto en la década de los ' 90 no pasaba tanto. A partir de ahí te genera automáticamente mayor movimiento, mayor crecimiento, mayor enriquecimiento y mayor conflictividad porque algunos son opositores a la conducción y otros son favorables a la conducción del sindicato y algunos sindicatos son más permeables a los disidentes y hay quienes no los quieren ni ver y entonces los ponen en situaciones donde la

\footnotetext{
31 El Observatorio del Derecho Social de la CTA-A muestra un incremento en la participación de delegados en la firma de negociaciones a nivel de empresa, del 36\% en 2006 al 56\% en 2015. Observatorio Del Derecho Social (CTA-A), Disparen contra el trabajo (y contra los trabajadores). Conflictos laborales, negociación colectiva y mercado de trabajo -Informe Anual 2016, 2016, CTA-A.

32 Véase Adolfo Gilly, "La anomalía argentina (Estado, corporaciones y trabajadores)”, Pablo González Casanovas (Comp.) El Estado en América Latina. Teoría y Práctica, México, Siglo XXI Editores, Universidad de las Naciones Unidas, 1990, 187-213.
} 
conflictividad se torna alta y a veces con los trabajadores de por medio en algunos lugares de trabajo.

Entrevista, Abogado sindical, 22 de octubre de 2010

La mayor organización en los lugares de trabajo es un aspecto mencionado por las distintas categorías de entrevistados y pudo ser observado en encuentros y plenarios de delegados. Esta participación se refleja en la dinámica de la negociación colectiva. Por ejemplo, la funcionaria citada, encargada de las negociaciones de diversas actividades industriales y de servicios, observaba esta "presión" o, al menos, "fiscalización" por parte de las bases obreras en los procesos de negociación: "Hay tal vez una mayor conciencia por parte del sector sindical de la necesidad de consulta a las bases, o de, no digo de necesidad, sino de necesaria participación. Es decir, hay, se nota que no hay una autonomía absoluta." (Entrevista, Funcionaria MTESS, 14 de mayo de 2014)

En base a los sectores analizados, esta activación de las bases obreras adopta distintas formas, y grados, de fiscalización, interés, participación, que, aun cuando no suponga una oposición a las dirigencias sindicales implica cierto control sobre su política gremial. Los procesos de activación de las bases surgen en muchos casos en oposición a dirigencias tradicionales burocráticas y otras veces resultan de un impulso de las dirigencias o intentos de renovación de sectores sindicales con el fin de ocupar el espacio de trabajo de modo de evitar un avance de sectores antiburocráticos y/o combativos.

En estos procesos, la propia participación y activación de las organizaciones de base constituye un proceso que presenta como potencialidad el cuestionamiento de las dirigencias. Es precisamente por ello que estas mismas dirigencias se plantearon estrategias respecto de la organización de base a través de la formación de delegados, de reuniones de consulta, asambleas, entre otras prácticas, reconociendo allí un problema central para su permanencia.

\section{Reflexiones finales}

En este trabajo buscamos problematizar la relación entre conflicto laboral y negociación colectiva en la Argentina reciente. Al respecto, pudimos observar la articulación del conflicto laboral en torno a los procesos de negociación colectiva e, incluso, la integración de los conflictos a la dinámica de la negociación. Dadas las condiciones del mercado de trabajo en el período 2003-2015, con bajas tasas de desempleo abierto en relación con los años '90, las negociaciones paritarias suelen estar precedidas y acompañadas por medidas de conflicto laboral que forman parte de las estrategias sindicales con respecto al proceso de negociación colectiva. En este sentido, la institucionalización de la lucha de clases, no significa que desaparezca toda expresión de conflicto o sea neutralizado completamente, sino que la conflictividad se despliega y desenvuelve, precisamente, moldeada por las instituciones que regulan las relaciones laborales.

A lo largo del período estudiado es posible observar una tensión existente entre una suerte de "rutinización" de la dinámica de negociación y conflicto, y la activación de las bases obreras, activación que excede significativamente el alcance de las expresiones 
combativas. Los procesos de activación de base durante la década pasada implicaron abrir la participación y politización de los trabajadores en los lugares de trabajo y, y con ellas, el desarrollo de diversas tensiones entre bases y dirigencias o bien entre sindicatos locales y federaciones, que no necesariamente expresan el conflicto entre sectores de izquierda o combativos y burocracias sindicales, sino que muchas veces se desarrollan en el marco de una orientación político-gremial que oscila entre el conflicto y la negociación, entre la confrontación y la conciliación, sin cuestionar necesariamente a las dirigencias sindicales tradicionales.

Esta activación de las bases obreras abrió una tensión con las dirigencias y las prácticas sindicales tradicionales que marcó la dinámica del conflicto y la negociación colectiva en el período. Los procesos de descentralización de la negociación y del conflicto laboral expresan, precisamente, la importancia de la organización en los lugares de trabajo. Sin embargo, como mencionamos en nuestro trabajo, esto no supone necesariamente una tensión entre bases y dirigencias. El alcance de estas tensiones y su impacto en la estructura sindical aún son objeto de debates y requieren profundizar en la investigación de las distintas experiencias desarrolladas en las primeras décadas del s. XXI.

\section{Referencias}

Paul Ackers, "Collective bargaining as industrial democracy: Hugh Clegg and the political foundations of British Industrial Relations pluralism", British Journal of Industrial Relations 45 (1), 2007, 77-101.

Perry Anderson, "Alcances y limitaciones de la acción sindical", Alessandro Pizzorno, Perry Anderson, Serge Mallet, y Franco Momigliano, Economía y política en la acción sindical, Cuaderno N 44. Buenos Aires, Ediciones Pasado y Presente, 1973, 57-73.

Maurizio Atzeni, y Pablo Ghigliani "The re-emergence of workplace based organisation as the new expression of conflict in Argentina", Gregor Gall, New Forms and Expressions of conflict at work, London, Palgrave Macmillan, 2013, 66-85

Alberto Bonnet, La insurrección como restauración. El kirchnerismo 2002-2015. Buenos Aires, Prometeo, 2015.

Mariela Cambiasso, Tradición de organización y estrategias sindicales. Un estudio sobre la organización sindical en la fábrica alimenticia Kraft-Mondelez (ex Terrabusi) en la postconvertibilidad, Tesis de Doctorado no publicada, Universidad de Buenos Aires, 2015.

Hugh A. Clegg, Sindicalismo en un sistema de negociación colectiva, Madrid, Ministerio de Trabajo y Seguridad Social, 1985.

Manuel Compañez, Patricia Ventrici y Federico Vocos, Metrodelegados. Subte: de la privatización al traspaso. Buenos Aires: Editorial Desde el Subte, 2012

Heather Connolly y Ralph Darlington, "Radical political unionism in France and Britain: A comparative study of SUD-Rail and the RMT", European Journal of Industrial Relations, 18, 2012, 1-16.

María Celia Cotarelo, Argentina (1993-2010). El proceso de formación de una fuerza social, Buenos Aires, PIMSA-Imago Mundi, 2016.

Michel Crozier, "Sociología del sindicalismo", Friedman G. y Naville P. Tratado de Sociología del Trabajo T II. México, FCE, 1971, 172-194. 
Ralph Darlington, “The role of Trade Unions in Building Resistance: Theoretical, Historical and Comparative Perspectives", Maurizio Atzeni Workers and Labour in Globalised Capitalism. Contemporary Themes and Theoretical Issues. London, Palgrave Macmillan, 2014, 111-138.

John T Dunlop, Sistemas de relaciones industriales, Barcelona, Ed. Península, 1978.

John T. Dunlop y Neil W. Chamberlain, Las negociaciones colectivas, Buenos Aires, Ediciones Marymar, 1971.

Lucila D’Urso, ¿Renovación de las estrategias sindicales en Argentina y Brasil? Los casos del SMATA y del Sindicato dos Metalúrgicos de ABC (2003-2014). (Tesis de Doctorado no publicada), Facultad de Ciencias Sociales, Universidad de Buenos Aires, 2017;

Lucila D'Urso y Julieta Longo, “The radical political unionism as renewal strategy in Argentina". Latin American Perspectives, November 13, 2017, 1-17

Matías E. Eskenazi, “Acumulación de capital y conflictividad laboral en argentina 2002-2009: Ejercicio de periodización e hipótesis de trabajo", XXVIII Congreso ALAS, Recife, Brasil, 2011.

Sebastián Etchemendy y Ruth Bernis Collier, "Golpeados pero de pie. Resurgimiento sindical y neocorporativismo segmentado en Argentina (2003-2007)", Posdata 13, 2008, 145192.

Allan Flanders, "What are trade unions for?", Management and unions, London, Faber and Faber, 1975, 38-47. "Collective bargaining: a theoretical analysis", British Journal of Industrial Relations, Vol. 6, No 1, 1968, 1-26.

Adolfo Gilly, "La anomalía Argentina (Estado, corporaciones y trabajadores)", Pablo González Casanovas (Comp.) El Estado en América Latina. Teoría y Práctica, México, Siglo XXI Editores, Universidad de las Naciones Unidas, 1990, 187-213.

Antonio Gramsci, Escritos periodísticos de L'Ordine Nuovo, Buenos Aires, Tesis Once, 1991.

Richard Hyman, Relaciones Industriales. Una introducción marxista, Madrid, Blume Ediciones, 1981

John Kelly Rethinking industrial relations: mobilization, collectivism and long waves, London, Routledge, 1998.

Paula Lenguita y Santiago Duhalde, "El clasismo sindical en tiempos kirchneristas. Un estudio de caso". Conflicto social 7 (enero-junio), 2012, 43-68.

Clara Marticorena, "Contribución al debate sobre la organización de base en la Argentina reciente a partir de la dinámica sindical en el sector químico", Conflicto Social 10 (18), 2017, 224-257.

"'Revitalización sindical y negociación colectiva en Argentina (2003-2011)". Perfiles Latinoamericanos 46, 2015, 173-195.

"Avances en el estudio de la relación entre sindicalismo y kirchnerismo", Sociohistórica. Cuadernos del CISH 36, 2015, 1-22.

argentina, de los '90 a la posconvertibilidad, Buenos Aires, Imago Mundi, 2014. 
- "Relaciones de fuerza, relaciones laborales y estructura de la negociación colectiva. Alcances y características de la descentralización en Argentina". Trabajo y Sociedad 23 (XVII), 2014, 127-145.

Clara Marticorena y Lucila D’Urso, “Alcances y límites de los procesos de reorganización sindical en la Argentina: de la crisis del 2001 a la recomposición de la agenda neoliberal", Revista da ABET. Brazilian Journal of Labour Relations, V. 17, N 2, Dossier Sindicalismo, 2018, 236-262.

John Mc Ilroy, "Radical political unionism reassessed", European Journal of Industrial Relations, 22, 2012, 251-258.

Ministerio de Trabajo, Empleo y Seguridad Social (MTEySS), Metodología para el relevamiento, sistematización y análisis de los conflictos laborales colectivos, MTEySS, 2018, 2.

Observatorio Del Derecho Social (CTA-A), Disparen contra el trabajo (y contra los trabajadores). Conflictos laborales, negociación colectiva y mercado de trabajo -Informe Anual 2016, 2016, CTA-A.

Programa de Investigación sobre el Movimiento de la Sociedad Argentina (PIMSA) "Los hechos de rebelión en Argentina 2002-2007", en Documentos y Comunicaciones, PIMSA, 2007.

Ricardo Spaltenberg, "La diversidad de los conflictos laborales: dispersión y centralización en las lógicas de acción de los asalariados privados". Trabajo, ocupación y empleo, 11, 2012, 95-118.

Cecilia Senén González y Andrea Del Bono (Coord.), La revitalización sindical en Argentina. Alcances y perspectivas. Buenos Aires, Prometeo/ UNLAM, 2013.

David Trajtemberg, Cecilia Senén González, Carla Borroni y Gabriela Pontoni, "Representación sindical en los lugares de trabajo: un análisis del Módulo de Relaciones laborales", Trabajo, ocupación y empleo 11, 2012, 119-142.

David Trajtemberg, Bárbara Medwid y Cecilia Senén González," La expansión de la afiliación sindical: Análisis del módulo de relaciones laborales de la EIL", Trabajo, ocupación y empleo 8, 2009, 13-34.

David Trajtemberg, Fabián Berhó, Paula Attorressi y Walter Lauphan, “Encuesta de Relaciones Laborales", ponencia presentada en el $7^{\circ}$ Congreso Nacional de Estudios del Trabajo, ASET, Buenos Aires, 2005

Martin Upchurch, y Andy Mathers, "Neoliberal Globalization and Trade Unionism: Toward Radical Political Unionism?" Critical Sociology, 38 (2), 2012, 265-280.

Paula Varela, La disputa por la dignidad obrera. Sindicalismo de base fabril en la zona norte del Conurbano bonaerense 2003-2014. Buenos Aires, Imago Mundi, 2015. -- (Coord.), El gigante fragmentado. Sindicalismo, trabajadores y política durante el kirchnerismo. Buenos Aires, Editorial Final Abierto, 2016. 